\title{
Change Management And Post-Merger Organizational Outcomes: Four Organizations Merge Into One
}

Ashley J. Bennington, (Email: kfajb00@tamu.edu), Texas A\&M University, Kingsville George R. Wagman, (Email: docwagman@sbcglobal.net), Texas A\&M University, Kingsville

\begin{abstract}
Most merger and acquisition literature looks at financial and marketing strategies, while dismissing or ignoring the people-issues. This study examines post-merger employee organizational identification and attitudes about organizational communication relationships.
\end{abstract}

\section{INTRODUCTION}

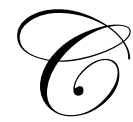

hange has become the standard for organizations in the 21st century. One aspect of organizational change-mergers and acquisitions - has garnered considerable attention in both popular and academic business literature. Organizational change management literature seeks both to gain better understanding of the types of changes that take place through merger and acquisition processes and to provide prescriptive guides for change managers.

Non-profit mergers are very similar to private and public sector organizational mergers in terms of purposes. The impetus behind most mergers is economic: economies of scale; administrative consolidation; and vertical and/or horizontal integration. The economic goals and results have received considerable attention in change management literature. However, less attention has been paid to how the employees are affected in merger processes.

This article examines a merger of four organizations one year after the new organization was established. The study makes two contributions to the change management literature through the analyses of 1) a multiple-organization merger and 2) post-merger workgroup attitudes. Change management implications of the results focus on communication strategies.

\section{MERGERS AND ANTICIPATED OUTCOMES}

A 1990 survey of merger and acquisition literature found that there was scant literature on the post-merger effects on the people who do the work of the organizations (Cartwright \& Cooper, 1990). The study points to the "fundamental factor of merger success - the combination of people, their expertise and their organizational culture (68)" and suggests that because mergers and acquisitions bring together different organizational cultures, more research is needed on the cultural dynamics. The acknowledgement of critical organizational issues involved with combining or integrating organizations continues in current merger literature (e.g. Kramer, Dougherty, \& Pierce, 2004). However, there is still little empirical data on how employees experience the new organization.

Mergers create organizational turmoil and employee anxiety. Twenty years ago, Buomno, Bowditch, \& Lewis (1985) argued that mergers and acquisitions frequently result in cultural collisions. Although organizational turmoil is expected in mergers, little research offers guidance for successfully managing the people-issues of the change. Marks and Mirvis (2001) assert that, "The lessons learned from past combinations are not being applied in a systematic manner to the management of current combinations (81)." They go on to point out that even when the merger involves organizational equals, managers get worried about losing status or having to change processes. One study found that $90 \%$ of the managers felt they were not prepared for the changes experienced (DiGiorgio 2003). 
When managers and supervisors have feelings of uncertainty, their feelings filter through the entire workforce. Organizational changes, even in the most positive of circumstances, cause employee insecurity.

Where there are studies of post-merger organizational issues, one of the pre-merger entities is usually found to dominate the new organization. The acquiring or more dominant organization tends to expect employees to assimilate into the dominant organizational culture (Cartwright \& Cooper, 1993). Some employees resist assimilation because they are in "culture shock," while others resist due to a lack of or inappropriate communications before and throughout the change (Cartwright \& Cooper, 1990). Organizational communication theory asserts that successful organizational assimilation is dependent on the employee gaining and applying the necessary knowledge of the culture (Jablin, 1987). Without strategic management communications, "cones of confusion are created throughout the organization (Mindszenthy \& Roberts, 2001, 3).”

Communication studies offer suggestions for pre- and post merger management communication with employees about the changes. Organizational communication perspectives have also pointed out how differences in pre-merger organizations may warrant different message strategies throughout the entire merger process (Zhu, May \& Rosenfeld, 2004). Again there is little empirical data from any sector-public, private, or non-profit—about how employees perceive communications in the merger process.

A recent study of several agencies offers the definition of a non-profit merger as the "result of a decision of two or more organizations to combine their operations in a permanent relationship (Golensky \& DeRuiter, 2002, p 170)." This definition accurately describes the AreaServe (pseudonym) merger. In addition to contributing empirical data on employees' post-merger experiences, this study offers a unique opportunity to examine the merger of four autonomous organizations into one.

\section{FOUR ORGANIZATIONS MERGE}

With the realization that many clients were being served by each of the four autonomous non-profit organizations, agency management and board members were motivated to create a one-stop service hub to streamline client access to the various services. Ultimately, four organizations were determined to have a good strategic and service fit. Based on regular assessments by the United Way, all of the organizations had long-standing, successful service records and were financially stable. The impetus for this multiple-organization merger was to streamline services for clients.

When the four organizations merged into AreaServe, each organization became a division of the new agency: Consumer Services Division; Housing Division; Life Skills Division; and Health Division. With one exception (a

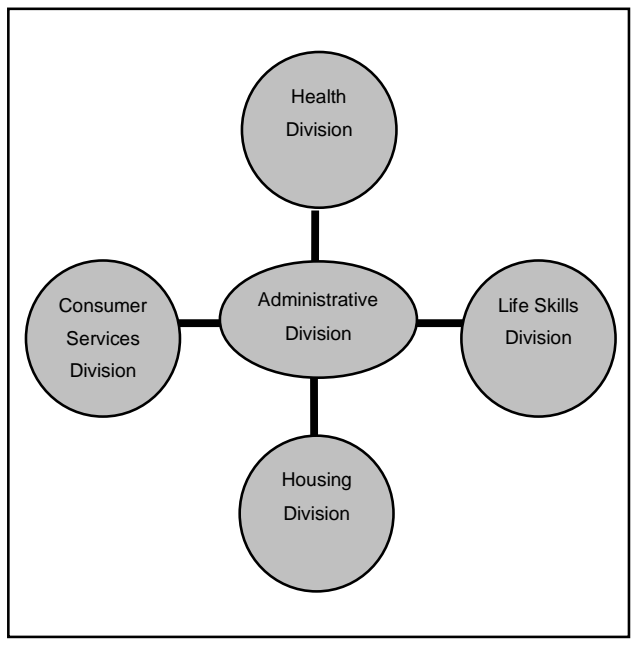

Figure 1 AreaServe Divisions retirement), the directors of the autonomous agencies became division directors in the new organization. Administrative functions were combined under a new executive director and the Administrative Division was created. As indicated in Figure 1, AreaServe pre-merger entities were basically interconnected through an umbrella administration, leaving the pre-merger entities with much the same functions after the merger.

During the formative process of this research, interviews with the director of human services of AreaServe revealed a concern about the level of unrest and dissatisfaction among Consumer Services Division staff members since the merger. During preliminary research and pilot study interviews, Consumer Services Division employees expressed considerable dissatisfaction with the new organization. Some said they felt like "orphans" or "step-children" to the larger organization, and that they felt isolated from the other divisions. These comments indicated a lack of connection or identification with the AreaServe entity. Considering that none of the pre- 
merger entities dominated in the post-merger agency, there was a question of what was different for the Consumer Services Division from the other divisions. The comments led to the more specific question of how employees in each division identified with the new organization.

\section{ORGANIZATIONAL IDENTIFICATION AND COMMUNICATION}

Organizational Identification (OID) is both a process and a product that can be described as "the nature of the individual's connection with the organization" (Cheney \& Tompkins, 1987, p.10). Studies indicate that the stronger an individual's sense of identification with an organization, the greater likelihood the individual will behave in ways that represent the best interests of the organization (Dutton, Dukerich, \& Harquail, 1994). This research finding is explained by the concept of organizational identification (OID), the social and psychological processes whereby members of an organization develop and maintain an attachment to an organization.

Organizational identification is a communicative process (Cheney \& Tompkins, 1987; Corman \& Scott, 1994; Scott, Corman, \& Cheney, 1998). It follows that the quality of communication relationships within an organization may also contribute to an employee's strength of organizational identification. These two conceptsorganizational identification (OID) and communication — give rise to the hypothesis.

Hypothesis: The quality of communication relationships indicated by each post-merger workgroup (division) will be positively related to the workgroup's organizational identification with the merged entity.

If this hypothesis is correct, the Consumer Services Division employees' identification with AreaServe and their perceptions of their communication relationship may provide insight into their general dissatisfaction.

\section{RESEARCH CONTEXT AND DESIGN}

This large nonprofit organization offers an opportunity to take a snapshot of the organization in its early formation and gather employees' perceptions of their communication relationships and identification with the new organization. The data were collected one year after the merger was official and structural changes were implemented.

Researcher access to AreaServe was granted by the executive director. Employees were notified of the research in several ways. The researcher was introduced at the one-year merger celebration picnic for all employees; a letter from the executive director supporting the research and encouraging participation was disbursed prior to the survey implementation. Additionally, the survey cover letter provided the explanation of the survey and human subjects' rights.

\section{The Survey}

Through the use of Cheney's (1983) Organizational Identification Questionnaire, we are able to learn how staff members evaluate their sense of loyalty, their feelings of commitment, and their solidarity with AreaServe, a nonprofit, social service organization. The quality of staff members' communication relationships in the organization was assessed with the communication relationships section of the International Communication Association organizational communication survey instrument. The focus of the communication relationships survey is on the individual's evaluation of the quality of his or her relationship with various levels within the organization.

Cheney's (1982) Organizational Identification Questionnaire was adapted to measure organizational identification. The name of the organization (AreaServe) was inserted into the appropriate items to objectify the survey. The Organizational Identification Questionnaire is a 25 -item questionnaire that measures organizational loyalty, solidarity, and commitment on 5-point Likert-type scale. The OID scale provides a 1-5 ranking indicating strongly disagree, disagree, neutral, agree, and strongly agree. On the AreaServe OID scale, an answer of 5 indicates the more positive response and 1 the more negative response. The three subscales are measured with multiple items: 9 items for loyalty (e.g., "I become irritated when I hear criticism of AreaServe"), 11 items for solidarity (e.g., "I have a lot in common with others employed by AreaServe"), and 5 items for commitment (e.g., "I really care about the fate 
of AreaServe"). The Organizational Identification Questionnaire has been shown to possess good psychometric properties (Cheney, 1983; Johnson et al., 1999).

The International Communication Association (ICA) organizational communication survey for the assessment of participants' communication relationships (CR) was modified to insert "AreaServe" in the appropriate items. The ICA-CR is a 17-item questionnaire that measures communication relationships on a 5-point Likert-type scale. The AreaServe CR scale provides a 1-5 ranking indicating strongly disagree, disagree, neutral, agree, and strongly agree. The CR scale has four subscales with multiple items: 1) 2 items for coworkers (e.g., "I trust my coworkers"), 2) 9 items for supervisor (e.g., "My immediate supervisor listens to me"), 3) 3 items for top management (e.g., "I trust top management"), and 4) 3 items for personal influence (e.g., "I have a say in decisions that affect my job"). The ICA survey reliabilities are well documented (DeWine, 1994).

The final section of the survey instrument collected demographic data including gender, age, ethnicity, education level, division, and position within the organization. Given the different primary functions of the five AreaServe divisions--Administration, Consumer Services, Housing Services, Life Skills, and Health Servicespotential differences among them became of interest.

\section{Data Collection}

All 179 staff members of AreaServe were given the opportunity to complete the survey instrument. The instrument and human subjects information letter were in an unsealed and labeled 9" x 12" manilla envelope; each staff member was instructed to seal the envelope with the completed survey. The researcher personally delivered the survey packets to each site and coordinated distribution and collection with site managers and/or office managers and returned the following week to pick them up.

A total of 97 surveys, out of a possible 179, were returned - a 54 percent rate of return. Of the 97 surveys received, five were not included due to incomplete responses. AreaServe participants for this study are 92.

Table 1

Frequency Distribution of Participants' Positions as a Function of AreaServe Division

\begin{tabular}{|c|c|c|c|c|}
\hline$\underline{\text { AreaServe Divisions }}$ & $\begin{array}{l}\text { AreaServe Posit } \\
\text { Administrative } \\
\text { Support }\end{array}$ & $\begin{array}{l}\text { Manager/ } \\
\text { Director }\end{array}$ & $\begin{array}{l}\text { Direct Service } \\
\text { Staff } \\
\end{array}$ & Total \\
\hline Administration & 12 & 10 & 0 & 22 \\
\hline Health Services & 4 & 5 & 22 & 31 \\
\hline Consumer Services & 5 & 3 & 4 & 12 \\
\hline Housing Services & 1 & 2 & 4 & 7 \\
\hline Life Skills & $\underline{2}$ & $\underline{3}$ & $\underline{8}$ & $\underline{13}$ \\
\hline Total & 24 & 23 & 38 & 85 \\
\hline
\end{tabular}

Seven participants did not identify their AreaServe position. Sixteen participants identified themselves as male, 74 as female; two respondents did not identify themselves by gender. Of the 85 percent (78) who responded to the item, participants reported ages from 18 years to 67 years. Of the demographic information collected, the data most surprising were for level of education. Of the 89 respondents indicating their level of education, 47 percent held graduate degrees, 36 percent held college degrees, and 15 percent held high school diplomas.

\section{RESULTS}

The first analysis was to determine differences in organizational identification (OID) among the five AreaServe divisions. A one-way ANOVA was performed on the mean OID scores as a function of AreaServe division,; the result indicated a significant between groups difference, $\underline{\mathrm{F}}(4,87)=3.43, \underline{\mathrm{p}}=.012$. As shown in Table 2, 
participants in the Administration division rated their own sense of Organizational Identification $(\underline{\mathrm{M}}=3.88, \underline{\mathrm{SD}}=.34)$ higher than those in the Consumer Services division $(\underline{\mathrm{M}}=3.46, \underline{\mathrm{SD}}=.43)$.

Next, a one-way ANOVA was performed on the mean Communication Relationship scores as a function of AreaServe division. The Levene test for this analysis indicated that the assumption of homogeneity of variance was violated, $\underline{\mathrm{F}}(4,87)=3.48, \mathrm{p}=.011$. Consequently, the Brown-Forsythe statistic was used which revealed a significant between groups difference, $\underline{F}^{*}(4,41)=4.47, \underline{p}<.01$.

Table 2

Means of Participants' Responses (Standard Deviations)

\begin{tabular}{llllll} 
AREASERVE DIVISIONS & \multicolumn{2}{c}{ OID } & & $\mathrm{N}$ \\
\hline & & & & & \\
Administration & $3.88^{\mathrm{a}}$ & $(.34)$ & $4.20^{\mathrm{a}}$ & $(.35)$ & 24 \\
Health Services & 3.66 & $(.34)$ & $\mathbf{3 . 4 3}^{\mathrm{a}}$ & $(.52)$ & $\mathbf{( . 9 2 )}$ \\
Consumer Services & $\mathbf{3 . 4 6}^{\mathrm{a}}$ & $\mathbf{( . 4 3 )}$ & 4.26 & $(.49)$ & $\mathbf{1 5}$ \\
Housing Services & 3.80 & $(.32)$ & 4.00 & $(.49)$ & 8 \\
Life Skills & 3.81 & $(.32)$ & 13
\end{tabular}

Note. Means in the same column for the OID scale sharing the same superscript differ at $\underline{p}<.05$ the Scheffe posthoc test. Means in the same column for the CR scale sharing the same superscript differ at $\mathrm{p}<.05$ in the Games-

Howell post-hoc test. Higher means represent more positive responses.

The subscales on the Communication Relationships instrument represent the respondent's evaluation of the quality of his or her communication relationships in four areas: communication with coworkers, communication with supervisor, communication with top management, and the individual's sense of personal influence through communication relationships.

Table 3

Mean of Communication Relationship Factors by Division

\begin{tabular}{lcccc} 
& Coworkers & Supervisor & Top mgmt & Influence \\
\hline AreaServe Division & & & & \\
Administration & 4.00 & 4.40 & 3.76 & 4.14 \\
Health Services & 3.98 & 4.26 & 3.45 & 3.77 \\
Consumer Services & $\mathbf{3 . 4 7}$ & $\mathbf{3 . 4 1}$ & $\mathbf{3 . 2 7}$ & $\mathbf{3 . 6 4}$ \\
Housing Services & 4.63 & 4.33 & 3.71 & 4.38 \\
Life Skills & 4.00 & 4.14 & 3.62 & 3.95 \\
Total & 3.96 & 4.15 & 3.55 & 3.92
\end{tabular}

The results confirm a positive relationship between organizational identification and communication relationships. That is, as the quality of communication relationships increases, so does organizational identification, and vice versa.

\section{DISCUSSION}

The AreaServe participants as a whole and within each division responded with a greater than neutral rating of organizational identification (OID). Overall, respondents report a positive sense of organizational identification. All divisions rated OID between neutral (3) and agree (4). The Consumer Services division, rating for OID was the lowest. This finding is consistent with the anecdotal evidence of dissatisfaction among Consumer Services staff subsequent to the merger. 
AreaServe participants from all divisions also indicated a greater than neutral rating for the quality of their communication relationships within the organization. On this scale, the Consumer Services Division rated the quality of communication relationships between neutral (3) and agree (4); the other four divisions all indicated ratings above agree (4). Participants also indicated on the CR section the degree to which they felt they had personal influence within the organization. An item example for personal influence is "I have a say in decisions that affect my job." Again, the Consumer Services division members ranked each of these subscales, on average, lower than any of the other four divisions.

One possible explanation for the lower level of identification with AreaServe may be in the characteristic of the culture of the Consumer Services division prior to the merger into the larger organization, which was not measured. Another possible source of discontent can be derived from the subscales of the Communication Relationships responses; employees in the Consumer Services Division indicated the lowest quality communication relationship with top management. However, the responses from this division indicated the lowest quality of all divisions in all four subscales, including communication relationships with coworkers. These results call for divisionspecific analysis; the source of discontent may have no direct relationship to the merger.

\section{LIMITATIONS AND FUTURE DIRECTIONS}

Of course there is limited generalizability from one study and additional data from this case may have enhanced the analysis. In retrospect, a set of baseline demographic data on all staff members by position and division might have shed light on the results. For example, the data do not show if all of the staff of individual divisions responded or a small percent of the entire staff. The response rate in the Consumer Service division could be important to the analysis. In addition, further understanding might be gained through semi-structured interviews.

Pre-merger data on the organizational identification in the Consumer Services Division might have shed light on the discontent. A study of post merger organizational identification and job satisfaction found that organizational identification with the pre-merger entity is important when that entity remains intact as a subunit in the newly formed organization (van Dick, Wagner, \& Lemmer 2004).

The data do not reveal a causal relationship between the quality of communication relationships and the strength of organizational identification. It is very difficult to tie OID as an effect back to a communicative antecedent. Even if we could identify potentially causal communication, the concept of organizational identification inherently requires a self-report, rendering inadequate any interpretations based on observation. However theory leads us to posit that the member's experiences in organizational communication relationships may influence that member's organizational identification, rather than vice versa.

There is a case to be made challenging the primarily positive connotations of OID found in much of the literature. However, continued research of the concept of identification management through communicative practices promises to provide greater understanding of both the process and product of organizational identification (Pratt, 2000).

Further studies may discern whether the quality of communication relationships within specific categories such as those in the CR scale - communication with coworkers, with supervisors, and with top management or sense of personal influence through communication-more directly influence organizational identification. The findings of this study suggest the communication behaviors of an organization's leaders, managers and supervisors are important variables for future examinations of organizational identification. Additional implementations of these two scales in organizational settings will help explain the nature of this relationship.

Given the research claiming leadership practices are fundamentally relational and communicative (Bennis \& Nanus, 1985; Kouzes \& Posner, 1987; Wheatley, 1992), an OID study that examines the quality of communication relationships using this same CR survey along with a survey assessing leadership practices might lead to greater specificity about whether there are specific relationships within an organizational structure that more directly influence the strength of organizational identification. 
Johnson, Johnson, \& Heimberg (1999) define organizational identification "as a process of internal and external persuasion by which the interests of an individual merge with the interests of an organization, resulting in the creation of identifications based on those interests" (p.159). Scott (1997) suggests OID must be considered along with related targets of identification such as occupation and work group. One study of competing targets of identification found multiple targets of identification, including ethnicity, religion, and profession as well as work groups and organizations (Bennington, Carroll, Trinastich, and Scott 2000).

Because of the types of services provided, there are a large number of social workers and counselors whose sense of identification with their profession could compete with their organizational identification. In this case study, a social worker or counselor would have a professional obligation to make decisions in the best interest of the client, creating potential competition with the best interests of the organization.

Cheney's (1983) position that members with organizational identification will most likely make decisions in best interests of organization should also be examined in terms of multiple targets of identification. The Bennington et al. (2000) study suggests that ethnic and religious targets of identification can be in competition with participants' work group or employing organization. At this time, there are no instruments for measuring multiple targets of identification.

\section{CONCLUSION}

Strategic management communication literature promotes "consistent and proper message context (Mindszenthy \& Roberts 2001)." Even though the AreaServe merger did not eliminate jobs or change workgroup functions, there were a variety of anticipated rough spots and communication challenges throughout the process of combining and the first year of adjustment. However, the consistent dissatisfaction demonstrated by the Consumer Services division defied all attempts to diagnose the cause(s) and to respond to concerns expressed. We anticipated a low level of organizational identification with AreaServe, which we found. We also anticipated a low level of satisfaction with the quality of communication relationships between the Consumer Services Division and the top management of AreaServe. However, the finding of a low level of satisfaction with the quality of communication relationships among coworkers was not anticipated. This finding leads us to suspect that the dissatisfaction about the changes, which was continually expressed by Consumer Services employees, may not have been the product of the merger or subsequent changes; the Consumer Services division may have entered the merger process with dissatisfactions unrelated to the changes.

The hypothesis was supported by the results of the study: The quality of communication relationships indicated by each post-merger workgroup (division) is positively related to the workgroup's organizational identification with the merged entity. The broader implications of this finding for change management support calls for pre-merger studies of employee attitudes (Cartwright \& Cooper 1990) and greater attention to the people-issues (Marks \& Mirvis 2001).

By measuring the quality of AreaServe staff members' communication relationships with their coworkers, their supervisors, and top management, as well as measuring how they felt about their own personal communicative influence, the results of this study confirm a positive relationship between communication and OID and suggest that organizational communication influences organizational identification. This is a fertile ground for continued study from several perspectives-particularly in organizational communication, multiple targets of identification, identification management, and leadership practices.

\section{REFERENCES}

1. Bennington, A. J., Carroll, C. E., Trinastich, C. E., \& Scott, C. R. (2000). Managing multiple targets of identification. Paper presented at the International Communication Association Conference, Acapulco, Mexico.

2. $\quad$ Bennis, W. \& Nanus, B. (1985). Leaders: The strategies for taking charge. New York: Harper \& Row.

3. Buono, A. F., Bowditch, J. L., \& Lewis, J. W., III. (1985). When cultures collide: The anatomy of a merger. 


\section{Human Relations, 38, 477-500.}

4. Cartwright, S. \& Cooper, C. L. (1993). The role of culture compatibility in successful organizational marriage. Academy of Management Executive, 7(2), 57-70.

5. Cartwright, S. \& Cooper, C. L. (1990). The impact of mergers and acquisitions on people at work: Existing research and issues. British Journal of Management, 1, 65-76.

6. Cheney, G. (1982). Organizational identification as a process and product: A field study. Unpublished master's thesis, Purdue University.

7. Cheney, G. (1983). On the various and changing meanings of organizational membership: A field study of organizational identification. Communication Monographs, 50, 342-362.

8. Cheney, G. \& Tompkins, P. K. (1987). Coming to terms with organizational identification and commitment. Central States Speech Journal, 38(1), 1-15.

9. Corman, S. R. \& Scott, C. R. (1994). Perceived networks, activity foci, and observable communication in social collectives. Communication Theory, 4, 171-190.

10. DeWine, S. (1994). International Communication Association audit. In R. Rubin, P. Palmgreen, \& H. Sypher (Eds.), Communication research measures: A sourcebook (pp. 193-205). New York: Guilford.

11. DiGiorgio, R. M. (2003). Making mergers and acquisitions work: What we know and don't know - Part II. Journal of Change Management. 3(3), 259-274.

12. Dutton, J. E., Dukerich, J. M., \& Harquail, C. V. (1994). Organizational images and member identification. Administrative Science Quarterly, 39(June), 239-263.

13. Golensky, M. \& DeRuiter, G. L. (2002). The urge to merge: A multiple-case study. Nonprofit Management and Leadership, 13(2), 169-186.

14. Jablin, F. M. (1987). Organizational entry, assimilation, and exit. In F. M. Jablin, L. L. Putnam, K. H. Roberts, \& L. W. Porter (Eds.), Handbook of Organizational Communication, 679-740. Newbury Park, CA: Sage Publications.

15. Johnson, W. L., Johnson, A. M., \& Heimberg, F. (1999). A primary- and second-order component analysis of the Organizational Identification Questionnaire. Educational and Psychological Measurement, 59(1), 159.

16. Kramer, M. W., Dougherty, D. S., \& Pierce, T. A. (2004). Communication during a corporate merger: A case of managing uncertainty during organizational change. Human Communication Research, 30, 71-101.

17. Kouzes, J. M. \& Posner, B. Z. (1987). The leadership challenge. San Francisco, CA: Jossey-Bass.

18. Marks, M. L. \& Mirvis, P. H. (2001). Making mergers and acquisitions work: Strategic and psychological preparation. Academy of Management Executive, 15, 2, 80-92.

19. Mindszenthy, B. \& Roberts, G. (2001) Team leaders and the communication loop: Connecting with employees versus selling an idea. Strategic Communications Management,5(1).

20. Pratt, M. G. (2000). The good, the bad, and the ambivalent: Managing identification among Amway distributors. Administrative Science Quarterly, 45(2000), 456-493.

21. Scott, C. R. (1997). Identification with multiple targets in a geographically dispersed organization. Management Communication Quarterly, 10(4), 491-511.

22. Scott, C. R., Connaughton, S. L., Diaz-Saenz, H. R., McGuire, K., Ramirez, R., Richardson, B., Shaw, S. P., \& Morgan, D. (1999). The impacts of communication and multiple identifications on intent to leave: A multimethodological exploration. Management Communication Quarterly, 12(3), 400-435.

23. Scott, C. R., Corman, S. R., \& Cheney, G. (1998). Development of a structurational model of identification in the organization. Communication Theory, 8, 298-336.

24. Tompkins, P. K. \& Cheney, G. (1985). Communication and unobtrusive control in contemporary organizations. In R. D. McPhee \& P. K. Tompkins (Eds.), Organizational communication: Traditional themes and new directions (pp. 179-210). Beverly Hills, CA: Sage.

25. van Dick, R., Wagner, U., \& Lemmer, G. (2004). Research note: The winds of change-Multiple identifications in the case of organizational mergers. European Journal of Work \& Organizational Psychology, 13, 2, p. 121-138.

26. Wheatley, M. J. (1992). Leadership and the new science. San Francisco: Berrett-Koehler.

27. Zhu, Y., May, S. K., \& Rosenfeld, L. B. (2004). Information adequacy and job satisfaction during merger and acquisition. Management Communication Quarterly, 18(2), 241-270. 